\title{
PENGARUH KEPEMIMPINAN TANSFORMASIONAL, BUDAYA ORGANISASI, DAN KEPUASAN KERJA TERHADAP PRODUKTIVITAS KERJA KARYAWAN PADA PT. INTERTAMA TRIKENCANA BERSINAR MEDAN
}

\author{
THE INFLUENCE OF TRANSFORMATIONAL LEADERSHIP, \\ ORGANIZATIONAL CULTURE, AND JOB SATISFACTION ON \\ EMPLOYEE PRODUCTIVITY AT PT. INTERTAMA TRIKENCANA \\ BERSINAR MEDAN
}

\author{
WirdaLilia $^{\text {(*) }}$ Juli Wistian Lombu ${ }^{2)}$ Pujiono Napitupulu ${ }^{3)}$ \\ Anugrah Krismes Laoly ${ }^{4)}$ Andriani Nainggolan ${ }^{5)}$ \\ 1,2,3,4,5) Jurusan Manajemen SDM, Fakultas Ekonomi, Universitas Prima Indonesia \\ 1email : liliawirda@ymail.com
}

\begin{abstract}
ABSTRAK
Tujuan penelitian ini untuk mengetahui pengaruh kepemimpinan transformasional budaya organisasi, dan kepuasan kerja terhadap produktivitas kerja karyawan. Jenis penelitian ini menggunakan pendekatan kuantitatif dengan metode analisis deskriftif. Penelitian dilakukan di PT Intertama Trikencana Bersinar Medan di Jalan. Ternak Ayam No.2 Dusun III, Desa Tj. Selamat Kec. Sunggal Deli Serdang. Sumatera Utara. Theoretical sampling yang digunakan adalah rumus slovin. Data dianalisa menggunakan analisis regresi linier berganda yang terdiri dari Uji-t secara parsial dan Uji-F secara simultan. Hasil penelitian menyebutkan bahwa kepemimpinan transformasional dibutuhkan karyawan karena memiliki integritas untuk mengubah cara pandang. Penerapan budaya organisasi dilakukan melalui pemberdayaan dan budaya dengan nilai positif yang dapat diikuti seluruh anggota organisasi. Metode mempertahankan kepuasan kerja karyawan dengan melakukan seleksi penempatan sesuai dengan kemampuan serta memberi penghargaan sebagai apresiasi.

Kata Kunci : Kepemimpinan Transformasional; Budaya Organisasi; Kepuasan Kerja; Produktivitas.
\end{abstract}

\footnotetext{
ABSTRACT

The purpose of this study was to determine the effect of organizational culture transformational leadership, and job satisfaction on employee work productivity. This type of research uses a quantitative approach with descriptive analysis methods. The study was conducted at PT Intertama Trikencana Bersinar Medan at Ternak Ayam No.2 Dusun III, Desa Tj. Selamat Kec. Sunggal Deli Serdang. North Sumatra. Theoretical sampling used is the Slovin formula. Data were analyzed using multiple linear regression analysis consisting of partial $t$-test and F-test simultaneously. The results of the study mentioned that transformational leadership is needed by employees because it has integrity to change the way of thinking. Implementation of organizational culture is done through empowerment and culture with positive values that can be followed by all members of the organization. The method of maintaining employee job satisfaction by selecting placements according to ability and giving awards as an appreciation.

Keywords: Transformational Leadership; Organizational culture; Job satisfaction; Productivity.
} 
P-ISSN 2580 - 7781

E-ISSN 2615 - 3238

\section{PENDAHULUAN}

Perkembangan era globalisasi yang semakin pesat menjadikan sumber daya manusia sebagai faktor penting di berbagai bidang kehidupan, khususnya dunia organisasi maupun perusahaan. Dimana manusia akan menjadi penentu berhasil atau tidaknya organisasi untuk mencapai tujuannya. Penggunaan Sumber Daya Manusia (SDM), didalam suatu perusahaan harus dilakukan dengan profesional agar terwujudnya keseimbangan antara kebutuhan karyawan, tuntutan dan kemampuan organisasi, karena itu tenaga kerja menjadi investasi bagi perusahaan dalam meningkatkan produktivitas.

Produktivitas merupakan sesuatu yang penting untuk diperhatikan oleh perusahaan. Menurunnya produktivitas biasanya diakibatkan oleh tidak seimbangnya antara peran tenaga kerja yang dipakai dengan hasil yang dicapai, rendahnya keinginan karyawan untuk bekerja, kurangnya ketepatan waktu untuk menyelesaikan pekerjaan, beban pekerjaan yang tidak sesuai dengan kemampuan karyawan, serta kurangnya komunikasi yang baik antara pimpinan dan bawahan.

PT. Intertama Trikencana Bersinar (PT ITB) merupakan perusahaan yang bergerak di bidang peternakan dan pembibitan ayam broiler yang berkantor pusat di Jakarta Timur dan memiliki 20 anak cabang di Indonesia. Peneliti melakukan penelitian pada salah satu anak cabang perusahaan yaitu PT. Intertama Trikencana Bersinar Medan yang sudah berdiri sejak tahun 2010, beralamat di Jln. Ternak Ayam No.2 Dusun III, Desa Tj. Selamat Kec. Sunggal Deli Serdang 20352, Sumatera Utara.

Dari data produksi tahun 2018 terlihat bahwa perusahaan hanya mampu memenuhi target sebesar $94.75 \%$ saja. Perusahaan hanya memenuhi target produksi pada periode bulan Januari hingga Juni, sedangkan pada bulan Juli sampai Desember perusahaan mengalami ketidakstabilan dan kegagalan dalam mencapai target hal ini dikarenakan adanya wabah penyakit unggas serta adanya beberapa karyawan yang melakukan kesalahan dalam pemeliharaan dan pencegahan sehingga terjadinya banyak kematian, penyusutan populasi dan menurunnya kemampuan berproduksi. 
P-ISSN 2580 - 7781

E-ISSN 2615 - 3238

Agar perusahaan mampu mencapai target produksi maka produktivitas kerja karyawan harus ditingkatkan terlebih dahulu, ada baiknya perusahaan mempertimbangkan beberapa faktor diantaranya adalah kepemimpinan transformasional, budaya organisasi dan kepuasan kerja. Seorang pemimpin yang berperan untuk memberikan motivasi serta dapat melakukan perubahan kearah lebih baik merupakan sesuatu yang sangat diperlukan dalam perusahaan mengingat dengan adanya pemimpin diharapkan dapat mempengaruhi individu maupun kelompok untuk dapat bekerja secara maksimal untuk mencapai target dan tujuan perusahaan. Kepemimpinan transformasional menginspirasi pengikut mereka tidak hanya untuk mempercayai dirinya secara pribadi, tapi juga mempercayai potensi mereka sendiri untuk membayangkan dan menciptakan masa depan organisasi yang lebih baik. (Edison, 2017;96)

Dalam jurnal penelitian (Ashar Arsyad, Max O. Siwi, Harry J. Sumampouw, 2015), menyatakan bahwa kepemimpinan transformasional memotivasi bawahan untuk berbuat lebih baik, dengan maksud lain dapat meningkatkan kepercayaan atau keyakinan diri bawahan yang akan berpengaruh pada produktivitas kerja karyawan. Dengan adanya pemimpin yang mampu memahami karyawan, maka karyawan akan merasa senang dan tertantang untuk berbuat lebih baik lagi demi mendapatkan hasil semaksimal mungkin.

Selain sistem kepemimpinan, budaya organisasi juga mempengaruhi produktivitas, dikarenakan menjadi pedoman bagi karyawan untuk berinteraksi dalam melakukan aktivitas kerja. Budaya dalam suatu organisasi harus kuat mendukung tujuan dan nilai perusahaan yang dapat dipahami, diikuti dan dilakukan oleh para anggota organisasi. Karena budaya yang kuat dan positif sangat berpengaruh terhadap perilaku dan kinerja perusahaan. Menurut Sutrisno, (2018), budaya organisasi yang dikendalikan dengan benar sebagai motif manajemen akan berpengaruh dan menjadi motivasi bagi karyawan untuk berprilaku positif, dedikatif, dan produktif. Nilai budaya itu tidak dapat dilihat tetapi menjadi kekuatan yang mendorong perilaku untuk menghasilkan efektivitas kinerja. Sementara itu menurut Edison, (2017), budaya organisasi yang baik dan kuat akan memiliki disiplin dan loyalitas tinggi yang sangat menghargai norma- 
norma dan nilai-nilai serta saling menghormati sesama anggota dan ketaatan terhadap perintah atasan.

Menurut Umam, (2018), budaya organisasi dinamakan sebagai budaya perusahaan karena tidak bisa dipisahkan dengan kinerja (performance) dan Sumber Daya Manusia. Semakin baik budaya perusahaan, semakin kuat pula dorongan untuk berprestasi.

Kepuasan kerja juga berpengaruh terhadap produktivitas dikarenakan memiliki arti penting bagi perusahaan, adanya kepuasan kerja bagi karyawan diharapkan dapat meningkatkan produktivitas secara menyeluruh. Biasanya kepuasan kerja bersifat tersendiri, karena setiap karyawan mempunyai tingkat kepuasan yang berbeda, yang dapat diukur seperti kompensasi yang diterima, perasaan nyaman akan pekerjaan, nyaman karena keterikatan budaya kerja yang baik, puas terhadap atasan, adanya identitas di perusahaan, kepuasan atas keamanan kerja, serta kesempatan promosi. Menurut (Wibowo, 2018;424), kepuasan kerja menyebabkan produktivitas dikarenakan penelitian lebih difokuskan pada tingkat individu dari pada organisasi dan pengukuran tingkat individu atas produktivitas tidak mempertimbangkan semua interaksi dan kompleksitas dalam proses kerja.

Khaerul (Umam, 2018;198), menyatakan bahwa hubungan antara produktivitas dan kepuasan kerja sangat kecil, kepuasan kerja merupakan akibat, dan bukan merupakan sebab dari produktivitas. Produktivitas yang tinggi akan menyebabkan peningkatan dari kepuasan kerja hanya jika karyawan mempersepsikan bahwa ganjaran instrinsik (rasa telah mencapai sesuatu) dan ganjaran ekstrinsik (gaji) yang diterima terasa adil dan wajar, serta diasosiasikan dengan kerja yang unggul.

Dalam jurnal penelitian (Maulidar, Said Musnandi, Mukhlis Yunus, 2012), mengemukakan bahwa kepuasan kerja adalah suatu sikap dimana adanya rasa senang yang ditimbulkan setelah bekerja. Hal ini menggambarkan bahwa dengan adanya kepuasan kerja akan memberikan suatu dorongan kepada para pekerja untuk bekerja lebih baik.Dengan demikian akan meningkatkan produktivitas kerja karyawan. 
P-ISSN 2580 - 7781

E-ISSN 2615 - 3238

Pada penelitian ini, peneliti memfokuskan pada sistem kepemimpinan transformasional yang akan diterapkan, budaya organisasi serta memperhatikan kepuasan kerja karyawan yang ada di PT Intertama Trikencana Bersinar Medan. Apabila hal ini berjalan dengan lancar sesuai dengan perencanaan dan penerapannya maka diharapkan dapat meningkatkan produktivitas kerja karyawan. Tujuan penelitian ini antara lain:

1. Untuk mengetahui bagaimana peran manajer dalam meningkatkan produktivitas kerja karyawan PT. Intertama Trikencana Bersinar medan melalui sistem kepemimpinan transformasioal ?

2. Untuk mengetahui cara apa yang digunakan manajer PT. Intertama Trikencana Bersinar medan dalam menciptakan budaya organisasi yang mengandung nilainilai positif dan dapat diikuti oleh seluruh anggota organisasi ?

3. Untuk mengetahui Metode apakah yang tepat digunakan untuk meningkatkan kepuasan kerja bagi karyawan PT. Intertama Trikencana Bersinar medan ?

4. Untuk mengetahui Kendala apa yang dihadapi manajer PT. Intertama Trikencana Bersinar medan dalam melakukan peningkatan produktivitas kerja karyawan ?

\section{METODE PENELITIAN}

Jenis penelitian ini menggunakan pendekatan kuantitatif dengan metode analisis deskriftif, yaitu penelitian yang dimaksud untuk memahami variabel penelitian yang dipusatkan pada masalah-masalah dan fenomena yang sedang terjadi dengan bentuk penelitian berupa angka yang memiliki makna. Pendekatan kuantitatif adalah penelitian yang berdasarkan pada filsafat positivisme, digunakan untuk meneliti pada populasi atau sampel tertentu. Pengumpulan data menggunakan instrumen penelitian. (Sugiyono, 2017;17). Data dianalisis menggunakan regresi linier berganda dengan Uji-t secara parsial dan Uji-F secara simultan. 
Lokasi penelitian dilakukan pada karyawan PT. Intertama Trikencana Bersinar Medan yang beralamat di Jalan. Ternak Ayam No.2 Dusun III, Desa Tj. Selamat Kec. Sunggal Deli Serdang 20352, Sumatera Utara. Penelitian dilakukan pada Februari 2019 sampai April 2019 untuk survei dan observasi.

Teknik pengumpulan data yang digunakan dalam penelitian ini adalah dengan teknik wawancara, kuesioner dan studi kepustakaan.

Populasi dalam penelitian ini adalah seluruh karyawan di PT. Intertama Trikencana Bersinar Medan. Dimana jumlah karyawan sebanyak 165 orang. Teknik Penentuan jumlah sampel yang digunakan oleh peneliti dalam penelitian ini adalah berdasarkan metode Slovin sebagai alat ukur untuk menghitung ukuran sampel karena jumlah populasi yang diketahui lebih dari 100 responden dengan tingkat kesalahan 5\%. Berdasarkan hasil perhitungan maka didapat jumlah sampel 110 responden.

\section{HASIL PENELITIAN DAN PEMBAHASAN}

\section{Gambaran Umum PT Intertama Trikencana Bersinar Medan.}

Perusahaan awalnya berdiri pada tahun 1983 yang waktu itu bernama PT. Cipendawa Breeding Farm. Lalu pada tahun 1984 PT. Cipendawa Breeding Farm melakukan pembenahan besar dimana PT. Cipendawa Breeding Farm mulai dikenal dengan nama PT. Berlian Unggas sakti yang menjadikan Breeding Farm sebagai unit penghasil DOC final stock yang terjamin mutunya. Penerapan biosecurity melalui sistem sanitasi yang ketat memperlihatkan betapa PT. Berlian Unggas sakti berusaha keras untuk mengurangi kemungkinan terjadinya kontak dengan pihak luar, sehingga wilayah breeding farm diupayakan untuk menjadi wilayah yang steril dan higenis. Pada 12 April 2010, pihak PT. Berlian Unggas sakti menjual segala aset dan perusahaannya kepada PT. Intertama Trikencana Bersinar. Dimana PT. Intertama Trikencana Bersinar masih berdiri dan berjalan sampai sekarang 
P-ISSN 2580 - 7781

E-ISSN 2615 - 3238

Visi : Menjadi Perusahaan Internasional yang utama, tangguh, berdasarkan tuhan, diberkati dan menjadi berkat.

Misi : Bersama ayam mencerdaskan bangsa, bertindak kreatif dan inovatif selangkah lebih.

\section{Statistik Deskriptif}

Analisis statistik deskriptif bertujuan untuk mengetahui jawaban minimum, maksimum, rata-rata dan standart deviasi para responden yang dapat dilihat pada tabel berikut, yaitu :

Tabel: Descriptive Statistics

\begin{tabular}{llcccc}
\hline & N & Minimum & Maximum & Mean & Std. Deviation \\
\hline Kepemimpinan & 110 & 34 & 50 & 44.61 & 3.853 \\
Transformasional & 110 & 29 & 50 & 43.47 & 4.188 \\
BudayaOrganisasi & 110 & 21 & 49 & 38.60 & 4.869 \\
Kepuasan kerja & 110 & 35 & 59 & 47.14 & 5.139 \\
Produktivitas & 110 & & & & \\
Valid N (listwise) & & & & \\
\hline
\end{tabular}

Sumber : Output data diolah (2019).

Dari hasil output Tabel diatas menunjukkan bahwa berdasarkan jawaban 110 responden maka hasil pengukuran variable Kepemimpinan Transformasional $\left(\mathrm{X}_{1}\right)$ diperoleh skor minimum sebesar 34, skor maximum sebesar 50, mean sebesar 44,61 dan standar deviasi sebesar 3,853. Hasil pengukuran variable Budaya Organisasi $\left(\mathrm{X}_{2}\right) 110$ responden diperoleh skor terendah (minimum) sebesar 29, skor maximum sebesar 50, mean sebesar 43,47 dan standar deviasi sebesar 4,188. Hasil pengukuran untuk variable Kepuasan Kerja $\left(\mathrm{X}_{3}\right) 110$ responden diperoleh skor minimum sebesar 21, skor maximum sebesar 49 , mean sebesar 38,60, dan standar deviasi sebesar 4,869. Dan hasil pengukuran untuk variable Produktivitas (Y) 110 responden diperoleh skor minimum sebesar 35, skor maximum sebesar 59, mean sebesar 47,14 dan standar deviasi sebesar 5,139 . 


\section{P-ISSN 2580 - 7781}

E-ISSN 2615 - 3238

\section{Uji Normalitas}

Uji normalitas bertujuan untuk mengetahui apakah masing-masing variabel berdistribusi normal atau tidak (Ghozali, 2013:110). Uji normalitas diperlukan untuk melakukan pengujian variabel lainnya dengan mengasumsikan bahwa nilai residual mengikuti distribusi normal. Berdasarkan hasil Kolmogrov smirnov, diketahui nilai Asymp. Sig (2-tailed) sebesar 0,132 hasil tersebut lebih besar dari 0,05 yang artinya data berdistribusi secara normal.

\section{Uji Heteroskedastisitas}

Uji heteroskedastisitas bertujuan untuk menguji apakah dalam model regresi terjadi ketidaksamaan variancedari residual satu pengamat ke pengamat yang lain (Ghozali, 2013;139).

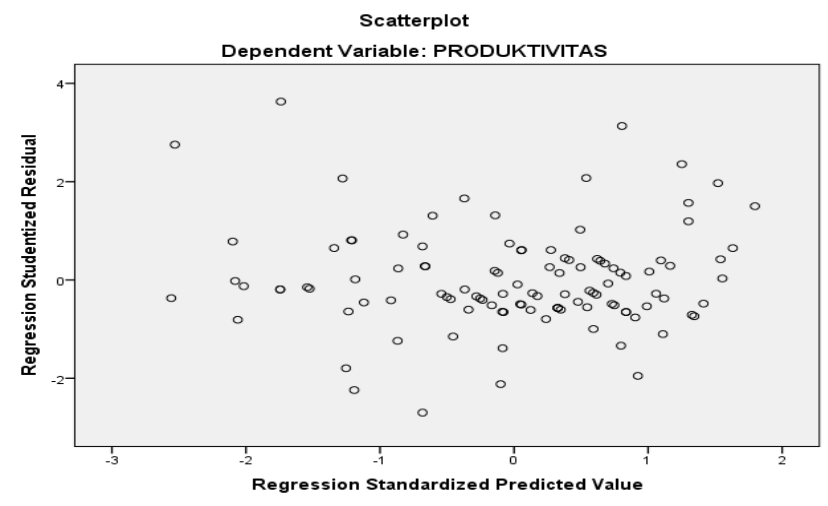

Sumber : Output data diolah (2019).

Dari hasil data diatas terlihat bahwa data tersebut menyebar secara acak dan tidak membentuk suatu pola. Data tersebar dibawah garis 0 pada sumbu Y dan menunjukan tidak terjadi heteroskedastisitas.

\section{Uji Multikolinearitas}

Uji multikolinearitas bertujuan untuk menguji apakah suatu model regresi terdapat kolerasi antar variable bebas (independen) (Ghozali, 2012;105) . Model regresi yang baik seharusnya tidak terjadi kolerasi antar variable independen. 
Hasil Uji Multikolinearitas

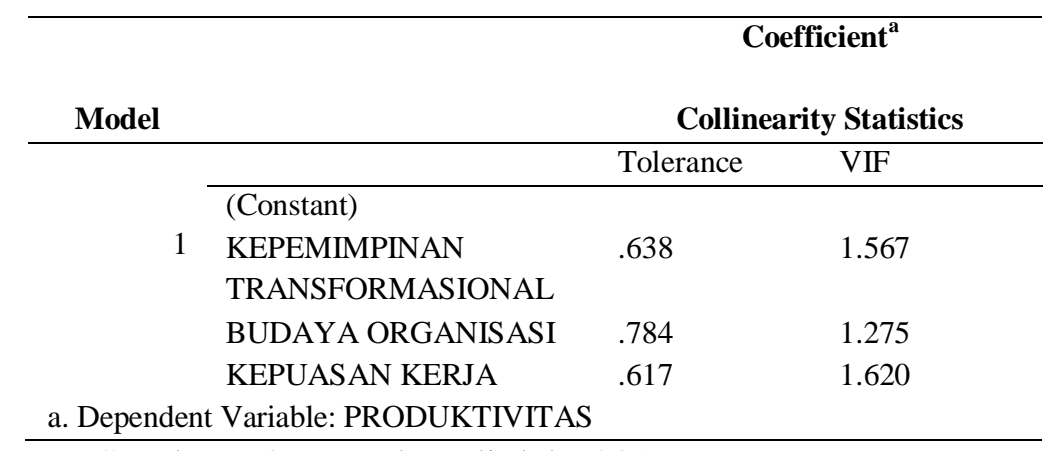

Sumber : Output data diolah (2019)

Berdasarkan pada hasil pengujian table diatas diperoleh nilai toleransi sebesar 0,638 untuk kepemimpinan transformasional, 0,784 untuk budaya organisasi dan 0,617 untuk kepuasan kerja, nilai tersebut lebih besar dari 0,10.

Sedangkan untuk hasil nilai VIF sebesar 1,567 untuk kepemimpinan transformasional, 1,275 untuk budaya organisasi dan 1,620 untuk kepuasan kerja, nilai tersebut lebih kecil dari 10 dan dapat disimpulkan bahwa tidak ada gejala multikolinearitas antar variable independen.

\section{Analisis Regresi Linier Berganda}

Model regresi digunakan untuk menguji pengaruh variabel bebas kepemimpinan transformasional, budaya organisasi, dan kepuasan kerja terhadap produktivitas. Pengujian menggunakan aplikasi Sofware SPSS Versi 20. Hasil pengujian dapat dilihat pada tabel dibawah ini :

Tabel : Hasil Uji Regresi Linier Berganda

\begin{tabular}{|c|c|c|c|}
\hline \multirow[b]{2}{*}{ Model } & & \multicolumn{2}{|c|}{ Unstandardized Coefficients } \\
\hline & & B & Std. Error \\
\hline & (Constant) & -6.538 & 3.488 \\
\hline & KEPEMIMPINAN & 0,582 & 0,086 \\
\hline 1 & TRANSFORMASIONAL & & \\
\hline & BUDAYA ORGANISASI & 0,301 & 0,071 \\
\hline & KEPUASAN KERJA & 0,379 & 0,069 \\
\hline
\end{tabular}

Sumber : Output data diolah (2019) 
P-ISSN 2580 - 7781

E-ISSN 2615 - 3238

Berdasarkan hasil diatas didapatkan model persamaan regresi sebagai berikut :

$$
\mathrm{Y}=-6.538+0,582 \mathrm{X}_{1}+0,301 \mathrm{X}_{2}+0,379 \mathrm{X}_{3}+e \ldots \ldots \ldots \ldots \ldots
$$

Penjelasan regresi linier berganda diatas adalah :

1. Konstanta (a) sebesar $-6,538$ yang berarti bahwa jika tidak terdapat nilai variabel kepemimpinan transformasional, budaya organisasi dan kepuasan kerja. Maka nilai produktivitas karyawan diperusahaan itu adalah -6,538.

2. Variabel kepemimpinan transformasional (X1) sebesar 0.582 yang berarti setiap kenaikan variabel kepemimpinan transformasional sebesar 1 persen Maka nilai produktivitas karyawan akan ikut naik sebesar 58,2 persen dengan asumsi bahwa variabel yang lain tetap.

3. Variabel budaya organisasi (X2) sebesar 0.301 yang berarti setiap kenaikan variabel budaya organisasi sebesar 1 persen. Maka nilai produktivitas karyawan akan ikut naik sebesar 30,1 persen dengan asumsi bahwa variabel yang lain tetap.

4. Variabel kepuasan kerja (X3) sebesar 0.379 yang berarti setiap kenaikan variabel budaya organisasi sebesar 1 persen. Maka nilai produktivitas karyawan akan ikut naik sebesar 37,9 persen satuan dengan asumsi bahwa variabel yang lain tetap.

Tabel : Uji $t$ dan Uji $f$

\begin{tabular}{|c|c|c|c|c|c|}
\hline \multicolumn{6}{|c|}{ Standardized Coefficients } \\
\hline \multicolumn{2}{|l|}{ Model } & Beta & $\mathbf{t}$ & Sig. & $\mathbf{F}$ \\
\hline \multirow{6}{*}{1} & (Contant) & & $-1,874$ & 0,064 & \\
\hline & KEPEMIMPINAN & 0,436 & 6,793 & 0,000 & \\
\hline & TRANSFORMASIONAL & & & & \\
\hline & BUDAYA & 0,245 & 4,230 & 0,000 & \\
\hline & ORGANISASI & & & & \\
\hline & KEPUASAN KERJA & 0,359 & 5,504 & 0,000 & 91,334 \\
\hline
\end{tabular}

Sumber : Output data diolah (2019)

Berdasarkan hasi pengujian tabel diatas, diperoleh nilai $F_{\text {hitung }}$ sebesar 91,334 dan $\mathrm{F}_{\text {tabel }}$ sebesar $1\left(\mathrm{df}_{1}\right) \mathrm{k}=3$, dan derajat bebas $2\left(\mathrm{df}_{2}\right)=\mathrm{n}-\mathrm{k}=110-3-1$ $=106$, dimana $n=$ jumlah sampel, $\mathrm{k}=$ jumlah variabel, maka nilai $\mathrm{F}_{\text {tabel }}$ pada taraf 
kepercayaan signifikansi 0,05 adalah 2,69. Dengan nilai signifikan 0,000. Artinya $91,334>$ 2,69. Maka Dengan demikian kepemimpinan transformasional $\left(\mathrm{X}_{1}\right)$, budaya organisasi $\left(\mathrm{X}_{2}\right)$, dan kepuasan kerja $\left(\mathrm{X}_{3}\right)$ secara bersama-sama berpengaruh terhadap produktivitas.

Secara parsial pengaruh masing-masing variabel dapat dilihat dari arah tanda dan tingkat signifikan (probabilitas) 0,05 pada derajat bebas $\mathrm{N}-\mathrm{k}(110-3$ $=107$ atau 1.658). Hasil pengujian hipotesis masing-masing variabel independen secara parsial terhadap variabel dependen dapat dianalisis sebagai berikut :

1. Pengujian secara parsial (uji t) untuk kepemimpinan transformasional terhadap produktivitas adalah nilai $t_{\text {hitung }}$ sebesar 6,793 dan nilai $t_{\text {tabel }}$ sebesar 1,658 maka nilai $t_{\text {hitung }}>t_{\text {tabel }}(6,793>1,658)$ dan nilai signifikan 0.000 lebih besar dari 0,05. Hal ini berarti hipotesis diterima yaitu : kepemimpinan transformasional secara parsial berpengaruh positif dan signifikan terhadap produktivitas kerja karyawan.

2. Pengujian secara parsial (uji t) untuk budaya organisasi terhadap produktivitas adalah nilai $t_{\text {hitung }}$ sebesar 4,230 dan nilai $t_{\text {tabel }}$ sebesar 1,658 maka nilai $\mathrm{t}_{\text {hitung }}>\mathrm{t}_{\text {tabel }}(4,230>1,658)$ dan nilai signifikan 0.000 lebih besar dari 0,05. Hal ini berarti hipotesis diterima yaitu : Budaya organisasi berpengaruh positif dan signifikan terhadap produktivitas kerja karyawan.

3. Pengujian secara parsial (uji t) untuk kepuasan kerja terhadap produktivitas adalah nilai $t_{\text {hitung }}$ sebesar 5,504 dan nilai $t_{\text {tabel }}$ sebesar 1,658 maka nilai $t_{\text {hitung }}>t_{\text {tabel }}(5,504>1,658)$ dan nilai signifikan 0.000 lebih besar dari 0,05. Hal ini berarti hipotesis diterima yaitu : Kepuasan kerja berpengaruh positif dan signifikan terhadap produktivitas kerja karyawan

Berdasarkan hasil uji diketahui nilai R Square sebesar 0,721, artinya bahwa variabel independen dapat menjelaskan variabel dependen sebesar 72,1 persen. Sedangkan sisanya 27,9 persen dijelaskan oleh variabel lainnya yang tidak diteliti dalam penelitian ini. Maka dapat disimpulkan bahwa 72,1 persen variabel produktivitas (Y) mampu dijelaskan oleh kepemimpinan transformasional (X1), budaya organisasi (X2), dan kepuasan kerja (X3) dan sisanya 27,9 persen dijelaskan oleh variabel lainnya. 
P-ISSN 2580 - 7781

E-ISSN 2615 - 3238

\section{Pembahasan}

Hasil perhitungan pengujian hipotesis secara parsial menunjukan bahwa kepemimpinan transformasional berpengaruh positif dan signifikan terhadap produktivitas. Penelitian ini sejalan dengan hasil penelitian yang dilakukan oleh (Ashar Arsyad et al., 2015) yang mengatakan bahwa kepemimpinan transformasional memotivasi bawahan untuk berbuat lebih baik, dengan maksud lain dapat meningkatkan kepercayaan atau keyakinan diri bawahan yang akan berpengaruh pada produktivitas kerja karyawan. Degan adanya pemimpin yang mampu memahami karyawan, maka karyawan akan merasa senang dan tertantang untuk berbuat lebih baik lagi demi mendapatkan hasil semaksimal mungkin. Pemimpin transformasional mengubah kesadaran para pengikut akan persoalan dengan membantu mereka memandang masalah lama dengan cara baru dan mereka mampu menggairahkan, membangkitkan para karyawan untuk mengeluarkan segala upaya demi mencapai sasaran kelompok (Defy Kurniawan, 2015).

Hasil perhitungan pengujian hipotesis secara parsial menunjukan bahwa budaya organisasi berpengaruh positif dan signifikan terhadap produktivitas. Penelitian ini sejalan dengan hasil penelitian yang dilakukan oleh (Jemi et al., 2018) menyatakan bahwa penurunan produktivitas memungkinkan apablila budaya organisasi didalam perusahaan lemah. Budaya organisasi dan nilai perusahaan melalui pemberdayaan, ketegasan, sikap belajar, dan tim kerja merupakan komponen budaya organsisasi yang kuat, budaya pada tingkat ini adalah tindakan nyata untuk produktivitas kerja karyawan yang unggul (Eviyan Ishani et al., 2012).

Hasil perhitungan pengujian hipotesis secara parsial menunjukan bahwa kepuasan kerja berpengaruh positif dan signifikan terhadap produktivitas. Penelitian ini sejalan dengan hasil penelitian yang dilakukan oleh (Mira Veranita dan Sri Janatun, 2013) yang menyatakan bahwa kepuasan kerja merupakan aspek penting pada diri seorang karyawan didalam sebuah perusahaan, karena kepuasan kerja akan mempengaruhi sikap kerja karyawan dalam bekerja seperti malas, lamban, rajin, produktif, lain-lain yang akan sangat mempengaruhi produktivitas 
karyawan itu sendiri maupun perusahaan. Hubungan kepuasan kerja terhadap produktivitas karyawan adalah positip, artinya setiap peningkatan kepuasan kerja memiliki peranan dalam upaya peningkatan produktivitas kerja karyawan (Kadek Super Nova Wardana et al., 2016).

\section{KESIMPULAN}

Berdasarkan hasil penelitian diatas, dapat disimpulkan bahwa kepemimpinan transformasional, budaya organisasi, dan kepuasan kerja secara bersama-sama berpengaruh dan signifikan terhadap produktivitas kerja karyawan pada PT. Intertama Trikencana bersinar Medan. Pemimpin dengan system kepemimpinan transformasional sangat berperan penting dalam mempertahankan dan meningkatkan produktivitas kerja karyawan karena umumnya karyawan akan merasa nyaman bekerja dibawah pimpinan yang mampu memotivasi dan mendorong karyawan untuk maju dengan prestasi kerja yang baik. Namun selain kepemimpinan harus pula didukung oleh budaya organisasi yang baik dan positif. Pemimpin berperan untuk bertindak tegas terhadap karyawan yang tidak mematuhi pola-pola, nilai-nilai, dan norma-norma yang merupakan bagian dalam budaya organisasi agar dapat meningkatkan produktivitas kerja karyawan sehingga akan berdampak pula pada kemajuan perusahaan. Dan akan semakin baik pula apabila kepuasan kerja karyawan positif karena karyawan yang memiliki kepuasan kerja yang baik akan lebih bergairah untuk maju serta bersedia mengikuti segala peraturan yang ada didalam perusahaan.

Maka bagi perusahaan khususnya pimpinan atau manajer bagian sumber daya manusia agar dapat mengelola karyawan dengan baik. Tetap tingkatkan kepemimpinan dengan gaya transformasional guna mencapai karyawan yang berkualitas, pemberdayaan dan ketegasan harus diterapkan dengan tepat agar budaya organisasi didalam perusahaan memilki nilai positif yang dapat diikuti oleh seluruh anggota organisasi, serta melaksanakan seleksi penempatan karyawan dalam bidang pekerjaan untuk menghindari kebosanan dan kejenuhan karyawan yang bekerja tidak sesuai bidangnya serta memperhatikan pemberian 
P-ISSN 2580 - 7781

E-ISSN 2615 - 3238

bonus dan penghargaan sebagai apresiasi atas usaha atau prestasi kerja yang telah dilakukan karyawan.

\section{DAFTAR PUSTAKA}

Ashar Arsyad, Max Siwi, Harry J. Sumampouw (2015). Pengaruh Kepemimpinan Transformasional dan Motivasi Terhadap Produktivitas Kerja Karyawan Pada PT Bintang Sewu Sejahtera di Manado. Jurnal Administrasi Bisnis.

Defy Kurniawan. (2015). Pengaruh Gaya kepemimpinan Transformasional dan Kompensasi terhadap Produktivitas Kerja Karyawan PT. Sport Glove Indonesia. Skripsi Manajemen Ekonomi Universitas Negeri Yogyakarta

Edy Sutrisno. 2018.“Budaya Organisasi”. Jakarta: Kencana. Prenadamedia Group. Emron Edison, Yohny Anwar, dan Imas Komariyah. 2017. "Manajemen Sumber Daya Manusia". Bandung: Alfabeta, Cv.

Eviyan Ihsani, Karma Syarif, S.E., M.M, Yetty Husnul Hayati S.E., M.M. (2012). Hubungan Budaya Organisasi dengan Produktivitas Kerja Karyawan Pada PT. Mitra Konservasi Indonesia (CICO RESORT). Jurnal studi Manajemen Sumber Daya Manusia. Pakuan Bogor.

Ghozali, Imam.2012. "AplikasiAnalisis Multivariate dengan Program IBM SPSS" Yogyakarta : Universitas Diponegoro.

Ghozali, Imam.2013.“Aplikasi Analisis Multivariate dengan Program IBM SPSS" Update PLS Regresi. Semarang: Badan Penerbit Universitas Diponegoro.

Jemi, Imanuel Tarigan, Syawaluddin. (2018). Pengaruh Budaya Organisasi dan Pelatihan terhadap Produktivitas Kerja Karyawan PT. Mitra Packindo Berdikari Medan. Jurnal Bisnis Kolega, 2476-910

Kadek Super Nova Wardana, Wayan bagia, Wayan Suwendra. (2016). Pengaruh Komunikasi Internal dan Kepuasan Kerja terhadap Produktivitas Karyawan. e-Journal Bisma Universitas Bisnis Ganesha.

Khaerul Umam. 2018. "Perilaku Organisasi”. Cetakan ke-3 Jawa Barat: Cv Pustaka Setia.

Maulidar, Said Musnandi, Mukhlis Yunus. (2012). Pengaruh Kepemimpinan dan Kepuasan Kerja Terhadap Motivasi Kerja dan Dampaknya Terhadap Produktivitas Pegawai Dinas Perindustrian Perdagangan Koperasi dan

Usaha Kecil Menengah Aceh. Jurnal Manajemen Pascasarjana Universitas Syiah Kuala. 2302-0199.

Mira Veranita, Sri Janatun. (2013). Pengaruh Kepuasan kerja terhadap Produktivitas Kerja Karyawan di Bank X. Jurnal Ekbis (Ekonomi Bisnis) 2339-1839

Sangadji, Etta Mamang, Sopiah. 2010. Metodologi penelitian pendekatan praktis dalam penelitian. Yogyakarta : andi.

Sugiono. 2012. "Metode Penelitian Pendekatan Kuantitatif, Kualitatif, dan R\&D". Bandung: Alfabeta, Cv. 
P-ISSN $2580-7781$

E-ISSN 2615 - 3238

Sugiono.2017. "Metode Penelitian Bisnis Pendekatan Kuantitatif, Kualitatif, dan" R\&D. Cetakan ke-15.. Bandung: Alfabeta, Cv.

Wibowo. 2018. "Manajemen Kinerja". Edisi 5. Cetakan ke-10 Jakarta: PT Raja Grafindo Persada. 